\title{
EFFECT OF CYTOKININS ON THE LIPID FATTY ACIDS OF LEAVES
}

\author{
Ulrich Kull and Roland BlXFNSTHIN \\ Biologisches Institut der Universitat Stuttgart, Stuttgart, Germany F R
}

(Recelved 19 March 1973 Accepted 29 June 1973)

Key Word Index - Coleus blumer Labiatae Impatiens sultam Balsaminaceae. Populus balsamtera Salicaceae. kınetın, zeatın, fatty acids lınolenıc dcid

\begin{abstract}
Kinetın and zeatin were administered to leaves of intact plants of Coleus, Impatiens and Populus in long-term experiments (4 weeks) and the variations of the tatty acid content of saponifiable lipids determined In the same species there are no significant differences between the effects of the two cytokinins In Impattens and Populus the content of linolenic acid increases The bohavioul of palmitic and linoleic acids is variable Coleus plants were treated with reatin at 15 and $25^{\prime}$ At the higher temperature the hormone causes a distinct rise of palmitic and a diminution of linolenic acid
\end{abstract}

\section{INTRODUCTION}

IT HAS been known for several years that in ageing leaves the synthesis of lipids is promoted by kinetin ${ }^{1}$ Although fatty acid synthesis is slightly inhibited in spinach chloroplasts incubated with kınetın, ${ }^{2}$ kinetin-treated spinach ledves contained more fatty acids than controls, which may be attributed mainly to an increase in the linolenate component of the plastids ${ }^{2}$ Plastids are known to be an important site of action of cytokinins, ${ }^{3-5}$ but they are not the only targets of these hormones in plant cells, for example in germınatıng wheat grains the catabolism of a part of the triglyceride reserves is induced by cytokınıns ${ }^{6}$ Earlier, in 5 out of 7 species investigated we found an increased amount of total lipids in leaves after the application of kınetın, ${ }^{7}$ but in several of these experiments the content of saponifiable lipids was lowered Continuing these investigations, the present study was designed to determine the long-term influence of kinetin and of the naturally occuring cytokinin zeatin on the fatty acid composition of saponifiable lipids of leaves

\section{RESULTS}

Leaves of intact plants of Coleus, Impatiens and Populus were treated with cytokinins (see Experimental) An influence of temperature on the effects of cytokinins is known from several reports ${ }^{8,9}$ One set of experıments with zeatin was therefore made with Coleus

'Li tham D S (1967) Anmu Re' Plant Phisiol 18, 349

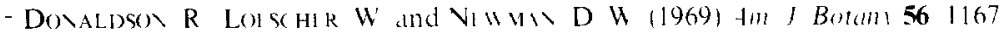

${ }^{3}$ Srivastava, B I S (1963) Alch Blochem Biophls 103, 200

${ }^{4}$ Dennis, D T, Stubis, M and Coultate T P (1967) Can J Botany 45, 1019

? Richyond A E SAChs B and OSBORN D J (1971) Phistol Plant 24, 176

- Tavener, R J A and Laidman, D L (1972) Phitochemt st , 11,981

${ }^{7}$ KL LL U (1972) Botan Studien $\left(J_{\text {enta }}\right)$ 19, 1

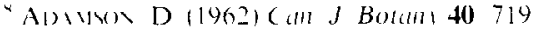

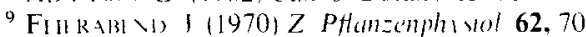


at a higher temperature than usual (25) This series is designated as "zeatin-warm" (Table 2) The fatty acid patterns are presented in Tables 1-4 as percentages of the total fatty acids, and for Coleus in Tables 1 and 2 also as the percentage of dry weight The fatty acid piofiles are in good agreement with those found in leaves of several higher plant species ${ }^{10}$ One notable deviation is the relatively low content of linolenic acid in Populus leaves

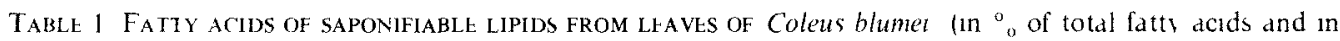
${ }^{\circ}$ "of dry wt) TREATFD WITH KINFTI (harvested in September)

\begin{tabular}{|c|c|c|c|c|c|c|c|c|}
\hline \multirow[b]{2}{*}{ Fatty deld } & \multicolumn{4}{|c|}{ no of total fatty atids } & \multicolumn{4}{|c|}{$10^{-2} n_{0}$ of $\mathrm{dry} w \mathrm{w}$} \\
\hline & Control & 100 ppm & $200 \mathrm{ppm}$ & $\mathrm{P}^{*}$ & Control & $100 \mathrm{ppm}$ & $200 \mathrm{ppm}$ & $P^{*}$ \\
\hline $100+101$ & 02 & 04 & 08 & 04 & 03 & 04 & 10 & 04 \\
\hline 120 & 04 & 06 & 13 & 19 & 05 & 06 & 16 & 20 \\
\hline 121 & 06 & 05 & 05 & 03 & 08 & 06 & 06 & 03 \\
\hline 170 & 15 & 12 & 11 & 04 & 20 & 14 & 14 & 04 \\
\hline 141 & 05 & 02 & 02 & 01 & 06 & 02 & 02 & 01 \\
\hline 160 & 319 & 319 & 280 & 286 & 410 & 383 & 339 & 298 \\
\hline 161 & 32 & 31 & 24 & 11 & 42 & 37 & 30 & 11 \\
\hline 163 & 05 & 04 & 05 & 05 & 06 & 05 & 06 & 06 \\
\hline 180 & 61 & 62 & 59 & 62 & 78 & 74 & 70 & 65 \\
\hline 181 & 39 & 38 & 52 & 60 & 50 & 46 & 63 & 63 \\
\hline 182 & 188 & 199 & 198 & 187 & 241 & 239 & 240 & 195 \\
\hline $18 ?$ & 318 & $31=$ & 345 & 348 & 408 & 372 & 418 & 363 \\
\hline Longer chain & 06 & 08 & 08 & 09 & 08 & 08 & 109 & 09 \\
\hline
\end{tabular}

* $10 \mathrm{ppm}$ solution (see Experımental)

A decrease in the content of the short-chain fatty acids (to $C_{14}$ ) was observed in several cases Only in one series (Impatiens-zeatin) did we find a rise, dependent on an increase of myistoleic acid (14 1) The behaviour of palmitic acid (160) is variable In Impattens the content decreases, in Colews, only in the series "zeatın-warm" is a significant increase to be seen In most cases no changes were found in the amounts of unsaturated $\mathrm{C}_{16}$-dcids The alterations of stearic (18 0$)$ and oleic (18 1) acids are variable and quantitatively not very important The linoleic acid (18 2) content decreases in Impatiens in leaves of Populus and in two out of three series of Coleus the content rises The amounts of linolenic deid (18 3) increase remarkably in Impatiens A small rise is found in Populis and kinetin-treated Coleus leaves In the zeatin experiments with the latter species decreasing amounts were found, especially in the "zeatın-warm" series The content of margarinic acid in Populus (see Ref 11 on the occui rence of margarinic acid in $P$ balsamufera) decreases in leaves

In Coleus leaves treated with kinetın and in the "zeatın-warm" serıes the total content of fatty acids decreases but in "zeatun-cold" the total content rises Therefore in the latter series the absolute content of all the important fatty acids increases (This is true for linolenic acid too, with the exception of the "P" series) For the other experiments with Coleus the contrat y is found

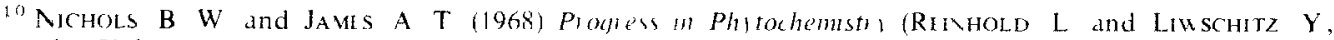
eds), Vol 1 p 1 Academic Press Ncu York

${ }^{11} \mathrm{~K}$ ILL L and Ji RI IIAS K (1972) Z Pflanzinphisiol 68, 55
} 
The proportion of multiple unsaturated $\mathrm{C}_{18}$-acids to palmitic acid ((18 $\left.\left.2+183\right) /(160)\right)$ is increased by kinetin in Coleus and Impatiens and by zeatin in the latter species In the zeatin experiments with Coleus, on the contrary, it decreases

TABLE 2 FATTY aCIDS OF SAPONifiable LIPIDS From LEAves of Coleus blume (in \% of total fatty acids and in $\%$ of dry wt), TREATED WITH ZEATIN AT $15^{\circ}$ (harvested in October) AND AT $25^{\circ}$ (harvested in March)

\begin{tabular}{|c|c|c|c|c|c|c|c|c|}
\hline \multirow[b]{3}{*}{ Fatty acid } & \multicolumn{8}{|c|}{$\%$ of total fatty dcids } \\
\hline & \multicolumn{4}{|c|}{$15^{\circ}$ (October) } & \multicolumn{4}{|c|}{$25^{\circ}$ (March) } \\
\hline & Control & $10 \mathrm{ppm}$ & $100 \mathrm{ppm}$ & $\mathrm{P}^{*}$ & Control & $10 \mathrm{ppm}$ & $100 \mathrm{ppm}$ & $\mathbf{P}^{*}$ \\
\hline $100+101$ & 02 & 03 & 02 & 01 & 27 & 26 & 24 & 07 \\
\hline 120 & 05 & 05 & 07 & 05 & \}$^{21}$ & 20 & 24 & 1 \\
\hline 121 & 06 & 05 & 04 & 01 & 21 & 11 & 13 & 07 \\
\hline 140 & 304 & & 04 & 09 & 06 & 04 & 05 & 04 \\
\hline 141 & $\int 04$ & 04 & 04 & 8 & 04 & 02 & 02 & 02 \\
\hline 160 & 285 & 272 & 281 & 275 & 157 & 201 & 221 & 225 \\
\hline 161 & 12 & 08 & 11 & 24 & 16 & 33 & 30 & 18 \\
\hline 163 & 09 & 07 & 09 & 03 & 14 & 10 & 12 & 15 \\
\hline 180 & 60 & 64 & 72 & 77 & 47 & 33 & 41 & 42 \\
\hline 181 & 45 & 46 & 56 & 77 & 34 & 30 & 26 & 34 \\
\hline 182 & 218 & 231 & 205 & 209 & 175 & 177 & 188 & 215 \\
\hline 183 & 348 & 347 & 336 & 309 & 486 & 441 & 412 & 417 \\
\hline \multirow[t]{2}{*}{ Longer chain } & 06 & 08 & 11 & 10 & 13 & 32 & 26 & 14 \\
\hline & \multicolumn{8}{|c|}{$10^{-2} \%$ of dry wt } \\
\hline $100+101$ & 02 & 03 & 02 & 01 & 76 & 46 & 36 & 16 \\
\hline 120 & 04 & 04 & 07 & 04 & 10 & 40 & 30 & \\
\hline 121 & 05 & 04 & 04 & 01 & 59 & 19 & 19 & 18 \\
\hline 140 & \}$_{03}$ & 03 & 04 & 04 & 16 & 06 & 07 & 10 \\
\hline 141 & 303 & & & & 11 & 03 & 04 & 04 \\
\hline 160 & 226 & 225 & 271 & 231 & 440 & 360 & 330 & 560 \\
\hline 161 & 10 & 07 & 11 & 20 & 45 & 58 & 45 & 45 \\
\hline 163 & 07 & 06 & 09 & 03 & 41 & 16 & 18 & 36 \\
\hline 180 & 47 & 53 & 69 & 64 & 130 & 59 & 60 & 105 \\
\hline 181 & 35 & 38 & 54 & 65 & 90 & 53 & 38 & 84 \\
\hline 182 & 173 & 192 & 198 & 175 & 500 & 310 & 480 & 503 \\
\hline 183 & 275 & 288 & 321 & 259 & 1380 & 790 & 610 & 1040 \\
\hline Longer chain & 04 & 06 & 11 & 09 & 38 & 30 & 38 & 35 \\
\hline
\end{tabular}

* See Experımental

\section{DISCUSSION}

There are no significant differences between the effects of kınetın and zeatin The decrease in the short-chain fatty acid content may be due to a stimulation of anabolic metabolism ${ }^{7}$ and may therefore be associated with an enhanced synthesis of longer chain acids However, this stimulation is in general not related to the increasing amounts of total fatty acids In comparing the "cold" and "warm" series of the Coleus zeatin experiments the relatively large differences in the controls (especially for palmitic and linolenic acids) cannot be explained Perhaps there is an influence caused by the different seasons, in which the experiments were made The patterns of the controls are contrary to what would be expected, for it is well known that increasing temperature causes a decrease of multiple unsaturated fatty acids and an increase of the saturated 
ones ${ }^{12-10}$ Within the "warm" series the effect of zedtin is analogous to that of increasing the temperature At the concentration applied, it seems possible that higher temperature will give rise to inhibitory effects of zeatin on synthesis of multiple unsaturated fatty acids

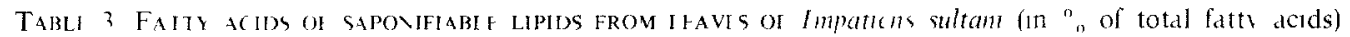

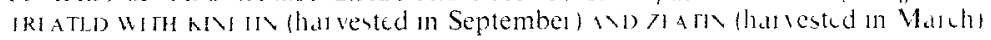

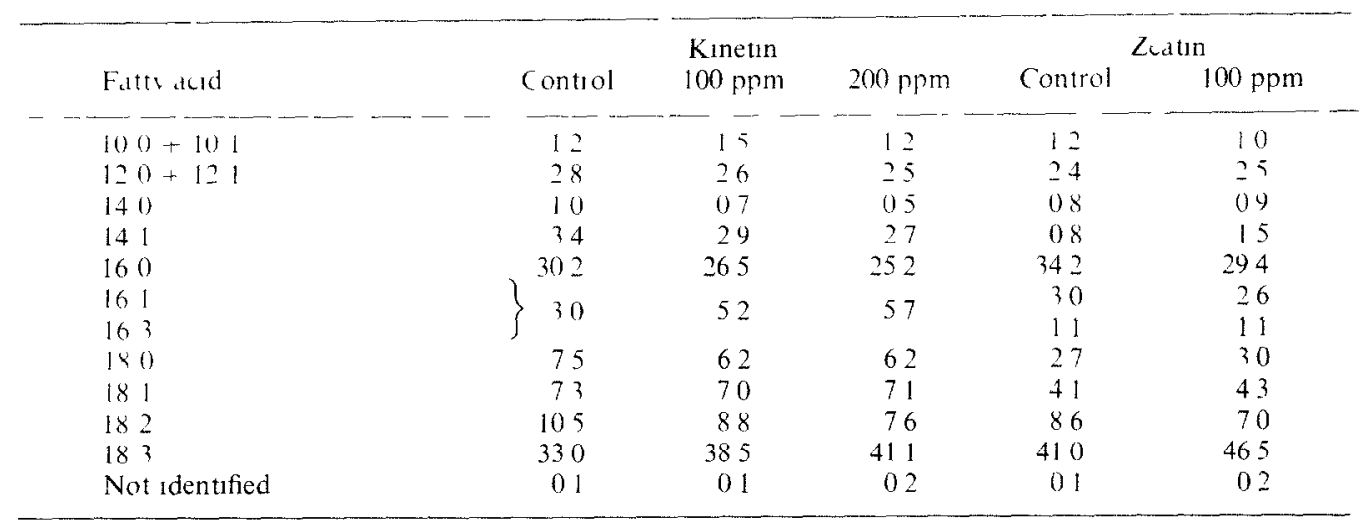

Donaldson et $\mathrm{al}^{2}$ after incubating leaves for $28 \mathrm{hr}$ with kinetın, found no enhancement of linolenate synthesis but the degradation was not as rapid as in control tissues In our experiments perhaps by rason of their long duration the ffect 1 not so obrous Moreover it is likely that a significant accumulation of linolenate in leaves lequires the avalability of either UDPglucose or UDPgalactose ${ }^{17}$ An effect of cytokinıns on

TABLF 4 FATTY ACIDS OF SAPONIFIABLI LiPIDS FROM LlAvLS OF Populus balsamfeia (in " of total fatt acids) TRIATHD WITH KI \FTIN (harvested in September)

\begin{tabular}{|c|c|c|c|}
\hline Fatty acid & Control & $100 \mathrm{ppm}$ & $200 \mathrm{ppm}$ \\
\hline $100+101$ & \}, 9 & & 16 \\
\hline $120+121$ & $\int 19$ & 21 & 16 \\
\hline $1+0$ & $1+$ & 11 & 05 \\
\hline 141 & 52 & 52 & 24 \\
\hline 160 & 228 & 229 & 257 \\
\hline 161 & 13 & 17 & 12 \\
\hline $163(\%)$ & 08 & 09 & 08 \\
\hline $170 \%$ & 224 & 230 & 160 \\
\hline 180 & 34 & 40 & 32 \\
\hline 181 & 30 & 36 & 55 \\
\hline 182 & 97 & 89 & 120 \\
\hline 183 & 258 & 251 & 279 \\
\hline Not identified & 23 & 15 & 12 \\
\hline
\end{tabular}

\footnotetext{
${ }^{12}$ HOLTON, R W, BllckrR, H H and ONORI M (1964) Phytochenusts 1 3, 595

${ }^{13}$ Grrloff E D Richardson T and Stahmand, M A (1966) Plant Phistol 41, 1280

${ }^{14}$ RMV R W 11969$)$ Plant Phl wol 4489

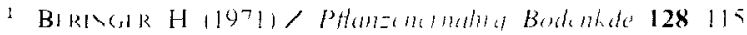

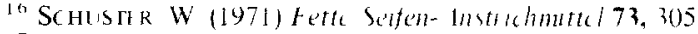

${ }^{17}$ Ovgi $\backslash 4$ and Me Di) J B (1968) J Bhol Chem 243, 1598
} 
the avalability of these sugar-nucleotides is very probable, because from several reports, 1t is known that they affect carbohydrate metabolism (e g, ${ }^{18,19}$ and further lit cited in Ref 7) In our long-term experiments there are also considerable changes in the contents of starch and sugars in leaves For experiments with kinetın this was described earlier ${ }^{7}$

The increase in linolenic acid content, which we found in several experiments with Impatiens and Populus, is in agreement with the data of Donaldson et al ${ }^{2}$ It is in accord with the well known effects of cytokinins on plastids, especially those of retardation of senescence Provided that cytokininsinhibit some kinases ${ }^{18}$ glucose-6-phosphate-1someidse and glucose-6-phosphate-dehydrogenase, ${ }^{19}$ a restriction of the glucose metabolism is to be expected Therefore more UDPglucose can be isomerized to UDPgalactose, the formation of which is prerequisite for an intensified synthesis of galactolipids, which contain the greatest proportion of linolenic acid

Cytokinins are known to have an influence on the properties of cellular membranes, e $g$ permeability and lon-transport ${ }^{5,20,21}$ It would be of interest to know whether one of the causes of this might be an alteration of the fatty acid composition of membrane lipids There is some evidence in this direction ${ }^{22}$ The great importance of the fatty acid composition for the properties of membranes was considered recently ${ }^{23,24}$ An approach to this problem can be made by short-term experiments and fractionation of the lipids

In some preliminary experiments carried out with the same material which gave the results described in this paper, an increase in the content of glycolipids and of some of the phospholipids and a decrease of the fraction of neutral lipids under the influence of zeatın was shown This agrees with earher results showing a rise in the content of lipidbound sugars in leaves after applicatıon of kınetın ${ }^{7}$

\section{EXPERIMENTAL}

Plant material Coleus blumer Benth, and Impatiens sultan Hook were propagated vegetatively from the clone used previously ${ }^{7}$ ' On application of cytokinins these plants were $5-7 \mathrm{~cm}$ high The investigations with Populus were made with homogeneous cutungs of Populus $\times$ halsamfena $\mathbf{L}$ CV Oxford ca $30 \mathrm{~cm}$ All plants were grown in flower pots under ndturd light in a greenhouse of the Botanical Garden The temp during the period of application was $15-18^{\circ}$ One set of experiments with Coleus ("zeatin-warm") was made at $d$ highe1 temp (ca $25^{\circ}$ ) in a hothouse

Application of cutokinins The application of kinetin and zeatin took place $4 \times$ in weekly intervals One week after administration of the last dose the plants were harvested and the material lvophilized The harvesting times are shown on the tables In the series named "P" $10 \mathrm{ppm}$ solutions of the cytokinin were administered by pencil to all green leaves of the plants In the other series only the young, not yet fully expanded leaves near the apex were treated with the solutions by a micropipette Each set included 7-10 plants of almost identical height and shape

Extraction of lipids and preparation for GLC Lyophilized leaves were extracted with $\left.\mathrm{CHCl}_{3}-\mathrm{MeOH}^{2} \mathrm{CH}^{2}\right)$ and the extract concentrated under red pres ${ }^{15} 26$ Saponification and esterification were accomplished as described by Kull and Jeremias ${ }^{11}$

GLC of fatty acid methyl esters A Varian Aerograph 1840-4 gas chromatograph, equpped with a hydrogen FID was used with a steel column $(6 \mathrm{~m} \times 3 \mathrm{~mm}), 10 \%$ EGSS-X on $60-80$ Chrom WAW-DMCS The column was maintained at $180^{\circ}$ injector at $200^{\circ}$ detector at $270^{\circ} \mathrm{N}_{2}$ flow $30 \mathrm{ml} / \mathrm{min}$ The identity of the compounds

18 Tuli, V Dilli Y D R and WitTwi R S H (1964) Sacnce 146, 1477

19 Simpkins, I and Strlft H E (1970) J Evp Botany 21, 170

${ }^{20}$ Ilan, I Gilad T and Reinhold L (1971) Phistol Plant 24, 337

21 ILAN, I (1971) Physiol Plant 25, 230

22 SChatfllk G W and Sharpl JR F T (1971) Phislol Plam 25, 456

${ }^{23}$ TrAl BII H (1971) Natumisemchatten 58, 277

${ }^{24}$ Krel i7 W (1972) Angen Chem 84.597

${ }^{25} \mathrm{Kl}$ Ll L (1971) Bi Dtsh Bot Ge, 84, 299

26 Wivtla E (1963) Z Lebensmitel-Cnte) 123,205 
was established by comparison of the retention times with those of the methyl esters of fatty acids and by co-injection with these standards ${ }^{11}$

Acknouledgements - Thanks are duc to Dipl Chem E Jenkins and to Mr P Cleary for their corrections of the Enghsh text dnd to the Deutsche For schungsgemeinschaft for tinancial support to the sentor author 